\title{
Association of vertebral compression fractures with physical performance measures among community-dwelling Japanese women aged 40 years and older
}

Kazuhiko Arima ${ }^{1 *}$ (D, Yasuyo Abe ${ }^{1}$, Takayuki Nishimura ${ }^{1}$, Takuhiro Okabe ${ }^{1,2}$, Yoshihito Tomita $^{1,2}$, Satoshi Mizukami ${ }^{1,2}$, Mitsuo Kanagae ${ }^{1,2}$ and Kiyoshi Aoyagi ${ }^{1}$

\begin{abstract}
Background: Numerous reported studies have shown that vertebral compression fractures are associated with impaired function or disability; however, few examined their association with objective measures of physical performance or functioning.

Methods: We examined the association of vertebral compression fractures with physical performance measures in 556 Japanese women aged 40-89 years. Lateral spine radiographs were obtained and radiographic vertebral compression fractures were assessed by quantitative morphometry, defined as vertebral heights more than 3 SD below the normal mean. Measures of physical performance included walking speed, chair stand time and functional reach. Adjusted means of performance-based measures according to the number and severity of vertebral compression fractures were calculated using general linear modeling methods.

Results: After adjusting for age, body mass index, back pain, number of painful joints, number of comorbidities and regular physical activities, the walking speed of women with two or more compression fractures $(1.17 \mathrm{~m} / \mathrm{s})$ was significantly slower than that of women without compression fracture $(1.24 \mathrm{~m} / \mathrm{s})(p=0.03)$. Compared with women without compression fracture, chair stand time was longer in women with two or more compression fractures $(p=0.01)$, and functional reach was shorter $(p=0.01)$. No significant differences were observed in walking speed, chair stand time, or functional reach between women with one compression fracture and those without compression fracture.

Conclusions: Having multiple vertebral compression fractures affects physical performance in communitydwelling Japanese women. Poor physical functioning may lead to functional dependence, accelerated bone loss, and increased risk for falls, injuries, and fractures. Preventing vertebral compression fracture is considered important for preserving the independence of older adults.
\end{abstract}

Keywords: Vertebral compression fractures, Physical performance, Walking speed, Chair stand time, Functional reach test

\footnotetext{
* Correspondence: kzarima-ngs@umin.ac.jp

${ }^{1}$ Department of Public Health, Nagasaki University Graduate School of

Biomedical Sciences, 1-12-4 Sakamoto, Nagasaki 852-8523, Japan

Full list of author information is available at the end of the article
} 


\section{Background}

Osteoporosis has been characterized as a skeletal disorder of reduced bone strength that leads to an increased risk for fracture [1]. The estimated number of patients with lumbar spine (L2-L4) and femoral neck osteoporosis in Japan was approximately 6.4 and 11 million, respectively [2]. Vertebral compression fracture is the most prevalent manifestation of osteoporosis [3]. Vertebral fractures were reported to occur in approximately $20 \%$ of postmenopausal women in populationbased studies [4-6], but two-thirds of vertebral fractures do not come to clinical attention [7, 8], because symptoms are absent or missed $[9,10]$. In Japan, medical and care expenditures on spine fracture were estimated at 9,895 hundred million yen [11],

Physical performance measures have been applied in geriatric studies. Poor physical performance measures are associated with medical problems [12], disability in activities of daily living (ADL) [13, 14], and increased risk of falls [15-17]. Thus, physical performance measures capture information about these physical factors above. In addition, the elderly with poor physical performance have an increased risk of hip and non-spine fractures and lower bone mineral density [18-20].

Numerous studies showed that vertebral compression fractures are associated with back pain, impaired function or disability [21-29], most of which used subjective measures, not objective ones. A few published studies examined the association of the number of vertebral compression fractures with objective measures of physical performance and functioning [23, 25, 26, 30]. We examined the association of the number and severity of vertebral compression fractures with objective measures of physical performance among community-dwelling Japanese women.

\section{Methods}

\section{Study design and participants}

The subjects were Japanese women aged 40-89 years who participated in the Hizen-Oshima Study. Details of the Hizen-Oshima Study have been published previously $[27,31]$. We recruited community-dwelling women aged 40 years and older in Oshima, Nagasaki prefecture, Japan. The women were identified by the municipal electoral list and were invited to participate through a single mailing. The town of Oshima has a population of approximately 5800; all women aged 40 and older (n >2000) were invited to participate. The examinations were performed at the Oshima Health Center between 1998 and 1999. A total of 586 women participated in the study. The mean age of participants (63.9 years) was significantly higher than that of non-participants (61.1 years). All participants were noninstitutionalized and living independently. All subjects gave written informed consent before enrolling. Recently, Cawthon et al. [30] reported that poorer physical performance was associated with an increased risk of incident radiographic vertebral fracture in men. We analyzed our baseline data of women in order to reinforce this evidence.

\section{Spine radiographs and vertebral compression fractures}

Lateral radiographs were obtained with the subject lying in a lateral decubitus position with knees bent. All radiographs were obtained using a tube-to-film distance of $105 \mathrm{~cm}$, with the tube positioned approximately over T8 for thoracic films and L-2 for lumbar films. The anterior, medial, and posterior heights of each vertebral body (T-4 to L-4) were measured on the lateral films with the aid of a microcomputer-linked caliper. Vertebral heights were measured on the thoracic film for thoracic vertebrae, and on the lumbar film for lumbar vertebrae. The points indicating the border of the vertebral centrum were chosen based on the procedure described by Gallagher et al. [32] and Spencer et al. [33]. Radiographic images were evaluated by one orthopedic surgical specialist (KA). A vertebral compression fracture was defined as a vertebra with at least one dimension (anterior, medial, or posterior height) more than 3 standard deviations (SDs) below the vertebra-specific population mean on the radiographs [34]. For example, the means and SDs of the anterior, medial, or posterior heights of subjects' T4 vertebrae were calculated. ([Mean anterior height of T4] - [3 $\times$ SD of anterior height of T4]; [mean medial height of T4] - [3× SD of medial height of T4]; and [mean posterior height of T4 - [3 $\times$ SD of posterior height of T4]) were calculated. Each calculated value was compared with the actual anterior, medial, or posterior height. If at least one dimension (actual anterior, medial, or posterior height) was less than the calculated value, it was regarded as a T4 vertebral compression fracture. Furthermore, based on the extent of vertebral height reduction, mild compression fracture was recorded as 3-4 SDs, and severe compression fracture as $>4$ SDs below the normal mean value. Mild vertebral compression fracture was defined as at least one mild compression fracture without severe compression fractures (at least one mild but no severe compression fracture). Severe vertebral compression fracture was defined as one or more severe compression fractures (at least one severe compression fracture).

\section{Measurements}

All participants were asked if they experienced back pain on most days during the previous month, and if they had any comorbidity, including cancer, heart disease, kidney disease, liver disease, diabetes mellitus, history of 
gastrectomy, thyroid disease, collagen disease, lung disease, stroke, or Parkinson's disease. Information on regular physical activity was collected; participants were asked whether they do any physical activity (e.g., walking, jogging, or bicycling) long enough to work up a sweat at least once a week. Information on the number of painful non-spine joints was based on the subject's response to the following question: "Which of your joints have ever been painful on most days during the previous month?" Specific response categories (shoulders, elbows, wrists, hands and fingers, hips, knees, ankles, and feet) for both sides of the body were provided on an illustration of the skeleton.

Measures of physical performance included walking speed (assessment of balance and lower extremity strength) [35], chair stand time (assessment of lower extremity strength) [36] and functional reach (assessment of balance and posture) [37], according to the previous report [19]. These performances are reported to be associated with balance, posture or lower limb strength [3539]. Women who had difficulty performing the test safely, such as needing a walking aid, recent lower limb fracture or operation or neurological comorbidity, were not examined. Trained physical therapists conducted the performance tests. Walking speed was calculated as the time required for subjects to walk a 6-m course bounded by two lines at their usual pace (average of two trials). Chair stand time was measured as the time it took (average of two trials) to stand up from a standard chair five times; the subjects were asked not to use their arms for assistance. Functional reach was calculated as the difference between two measurements (average of three trials), as follows: the subjects first stood comfortably upright, facing forward, hand in a fist, with their arm extended next to a yardstick mounted on a wall. They then reached forward as far as possible without stepping or losing their balance. Height and weight were measured in light clothing and without shoes. Body mass index (BMI) was calculated as weight $(\mathrm{kg}) /$ height $(\mathrm{m})^{2}$.

\section{Statistical analysis}

Women with missing values for any variables were excluded from analysis, leaving 556 women for data analysis. Analysis of variance (ANOVA) and multiple comparisons using the Tukey method for continuous variables and Fisher's exact test for categorical variables were used to determine the significance of differences among groups according to the number of vertebral compression fractures (no, one, and two or more). Age-specific means of physical performance measures were performed using ANOVA. Adjusted means of performance-based measures according to the number of vertebral compression fractures (no, one, and two or more) and the severity of vertebral compression fracture (no, at least one mild but no severe, and at least one severe) were calculated using general linear modeling methods (analysis of covariance). Age, BMI, back pain, number of non-spine painful joints, the number of comorbidities and regular physical activity was included simultaneously in the model as covariates. We examined the independent association of each variable above with physical performance measures. All statistical analyses were performed using SAS version 9.2 software (SAS Institute, Cary, NC, USA).

\section{Results}

Characteristics of subjects are shown in Table 1. The mean age of subjects was 64.4 years old. Mean walking speed was $1.24 \mathrm{~m} / \mathrm{s}$, mean chair stand time was $9.4 \mathrm{~s}$, and mean functional reach was $25.6 \mathrm{~cm}$. A total of $30 \%$ of the subjects had back pain, and $52 \%$ engaged in regular physical activity; $14.2 \%$ (79) had one or more vertebral compression fractures; $6.9 \%$ (38) had one compression fracture; and $7.4 \%$ (41) had two or more compression fractures. Women with vertebral compression fractures were significantly older, shorter and lighter than those without vertebral compression fracture. Women with vertebral compression fractures had significantly poorer physical performance (slower walking speed, longer chair stand time and shorter functional reach) and more prevalent back pain compared with those without vertebral compression fracture.

Table 2 shows mean and standard deviation (SD) of vertebral height, and \%height reduction values [(meanvertebral height)/mean] corresponding to mild (mean$3 \mathrm{SD}$ ) and severe (mean-4SD) vertebral fracture cutoffs for each vertebral dimension. Percent height reduction values corresponding to mild vertebral fracture cutoffs were between 20.3 and $38.3 \%$, and those corresponding to severe vertebral fracture cutoffs were between 27.0 and $51.0 \%$.

Physical performance decreased with age (Table 3); walking speed and functional reach decreased, and chair stand time increased (longer time required to complete the test represents a decline in function).

Table 4 shows the adjusted means of physical performance measurements according to the number of vertebral compression fractures. After adjusting for age, BMI, back pain, number of non-spine painful joints, the number of comorbidities and regular physical activity, the walking speed of women with two or more compression fractures $(1.17 \mathrm{~m} / \mathrm{s})$ was significantly slower than that of women without compression fracture $(1.24 \mathrm{~m} / \mathrm{s}) \quad(p=0.03)$. Compared with women without compression fracture, chair stand time was longer in women with two or more compression fractures $(10.4 \mathrm{~s}$ vs. 9.3 s) $(p=0.01)$, and functional reach was shorter $(23.2 \mathrm{~cm}$ vs. $25.9 \mathrm{~cm}) \quad(p=0.01)$. No significant 
Table 1 Basic characteristics of subjects according to compression fracture status $(n=556)$

\begin{tabular}{|c|c|c|c|c|}
\hline \multirow[t]{2}{*}{ Variable } & $\begin{array}{l}\text { Total } \\
(n=556)\end{array}$ & $\begin{array}{l}\text { No compression fracture } \\
(n=477)\end{array}$ & $\begin{array}{l}\text { One compression fracture } \\
(n=38)\end{array}$ & $\begin{array}{l}\text { Two or more compression } \\
\text { fractures } \\
(n=41)\end{array}$ \\
\hline & \multicolumn{4}{|l|}{ Mean (SD, 95\% Cl) } \\
\hline$\overline{\text { Age (years) }}$ & $64.4(9.5,63.6-65.2)$ & $63.1(9.3,62.3-64.0)$ & $69.5(6.9,67.2-71.8)^{a}$ & $73.6(7.1,71.3-75.8)^{a}$ \\
\hline Height $(\mathrm{cm})$ & $149.7(6.1,149.2-150.2)$ & $150.5(5.7,150.0-151.0)$ & $146.2(5.5,144.4-148.0)^{a}$ & $143.6(6.6,141.6-145.7)^{a}$ \\
\hline Weight (kg) & $52.4(8.7,51.7-53.1)$ & $53.1(8.7,52.3-53.9)$ & $49.7(7.6,47.2-52.2)^{a}$ & $46.8(7.4,44.5-49.2)^{a}$ \\
\hline Body mass index $\left(\mathrm{kg} / \mathrm{m}^{2}\right)$ & $23.3(3.4,23.1-23.6)$ & $23.4(3.5,23.1-23.7)$ & $23.2(3.5,22.1-24.4)$ & $22.6(2.7,21.8-23.5)$ \\
\hline Walking speed (m/s) & $1.24(0.25,1.22-1.26)$ & $1.26(0.24,1.24-1.28)$ & $1.17(0.28,1.08-1.26)$ & $1.05(0.24,0.97-1.13)^{a}$ \\
\hline Chair stand time (s) & $9.4(3.1,9.1-9.6)$ & $9.1(2.8,8.8-9.3)$ & $10.3(2.9,9.4-11.3)^{a}$ & $11.8(4.4,10.4-13.2)^{\mathrm{a}}$ \\
\hline \multirow[t]{2}{*}{ Functional reach $(\mathrm{cm})$} & $25.6(7.2,25.0-26.2)$ & $26.3(7.0,25.7-27.0)$ & $22.7(6.8,20.5-25.0)^{a}$ & $19.7(6.8,17.6-21.9)^{\mathrm{a}}$ \\
\hline & \multicolumn{4}{|l|}{ Number (\%) } \\
\hline Back pain & $164(29.5)$ & $128(26.8)$ & $18(47.4)^{b}$ & $18(43.9)^{b}$ \\
\hline Regular physical activity & $288(51.8)$ & $248(52.0)$ & $23(60.5)$ & $17(41.5)$ \\
\hline \multirow[t]{2}{*}{ Postmenopausal women } & $510(91.7)$ & $431(90.4)$ & $38(100.0)^{b}$ & $41(100.0)^{b}$ \\
\hline & \multicolumn{4}{|l|}{ Median (1st, 3rd quartile) } \\
\hline No. of non-spine painful joints & $0(0,2)$ & $0(0,2)$ & $0.5(0,2)$ & $0(0,2)$ \\
\hline No. of comorbidity & $0(0,1)$ & $0(0,1)$ & $0(0,1)$ & $0(0,1)$ \\
\hline
\end{tabular}

${ }^{a} P<0.05$ compared with no compression fracture (ANOVA \& Tukey method)

${ }^{\mathrm{b}} P<0.05$ compared with no compression fracture (Fisher's exact test)

differences were observed in walking speed, chair stand time, or functional reach between subjects with one compression fracture and those without compression fracture. In a multivariate model, slower walking speed was associated with older age, number of non-spine painful joints, number of comorbidities and lack of regular physical activity. Longer chair stand time was associated with older age, number of non-spine painful joints and lack of regular physical activity. Shorter functional reach was associated with older age. Additionally, we did the same analysis including upper or lower extremity joint pain instead of non-spinal painful joints. Slower walking speed was independently associated with number of upper and lower extremity joint pain, and chair stand time with lower extremity joint pain.

We also compared multivariate-adjusted means of physical performance measures according to severity of vertebral compression fracture. Women with severe vertebral compression fractures (at least one severe compression fracture) had significantly slower walking speed $(p=0.03)$ and longer chair stand time $(p=0.01)$ compared with women without compression fracture (data not shown). No significant differences were observed in walking speed and chair stand time between women with mild compression fracture (at least one mild but no severe compression fracture) and those without. Functional reach tended to be shorter in those with mild compression fracture $(p=0.06)$ and severe compression fracture $(p=0.08)$ than in those with no compression fracture. Women with severe vertebral compression fractures tended to have multiple vertebral compression fractures; median number (range) of vertebral compression fractures was $1(1-3)$ in women with mild vertebral compression fracture and $2(1-12)$ in those with severe vertebral compression fracture.

We examined multivariate-adjusted means of physical performance measures according to location of vertebral compression fracture (thoracic vs. lumbar). Longer chair stand time was associated with one thoracic compression fracture. Shorter functional reach was associated with two or more thoracic compression fracture.

\section{Discussion}

We showed that two or more vertebral compression fractures were associated with poor physical performance in walking speed, chair stand time, and functional reach. Huang et al. [25] reported that the number of recent vertebral fractures was associated with reduced functional reach and walking speed. Pluijm et al. [26] reported that the number of vertebral deformities was significantly associated with poor performance (cardigan test, walking test and chair stand test). These findings suggest that vertebral compression fracture affects various physical performance measures.

Previous studies have shown the relationship between vertebral compression fractures and impaired function (difficulty with activities of daily living [ADL]) or disability [21-29]. Poor physical performance test results (decreased functional reach and walking speed, and increased chair stand time) are reported to be predictors 
Table 2 Mean and standard deviation (SD) of vertebral height $(\mathrm{mm})$ and \% reduction values [(mean-vertebral height)/mean]

\begin{tabular}{|c|c|c|c|c|}
\hline & mean & SD & $\begin{array}{l}\text { Mild } \\
\text { \% reduction: } \\
\text { 100*[1 - (mean-3SD)/mean] (\%) }\end{array}$ & $\begin{array}{l}\text { Severe } \\
\% \text { reduction: } \\
100^{*}[1-(\text { mean-4SD)/mean }](\%)\end{array}$ \\
\hline T4A & 18.75 & 1.40 & 22.4 & 29.8 \\
\hline T5A & 19.10 & 1.50 & 23.6 & 31.5 \\
\hline T6A & 19.13 & 1.87 & 29.3 & 39.1 \\
\hline T7A & 19.43 & 1.90 & 29.4 & 39.2 \\
\hline T8A & 19.98 & 2.19 & 33.0 & 43.9 \\
\hline T9A & 20.80 & 2.11 & 30.5 & 40.7 \\
\hline T10A & 21.67 & 1.81 & 25.1 & 33.4 \\
\hline $\mathrm{T} 11 \mathrm{~A}$ & 22.30 & 2.10 & 28.3 & 37.7 \\
\hline $\mathrm{T} 12 \mathrm{~A}$ & 23.90 & 3.05 & 38.3 & 51.0 \\
\hline L1A & 26.19 & 3.07 & 35.2 & 46.9 \\
\hline L2A & 27.66 & 2.95 & 32.0 & 42.7 \\
\hline L3A & 28.77 & 2.49 & 26.0 & 34.6 \\
\hline L4A & 28.32 & 2.48 & 26.2 & 35.0 \\
\hline T4M & 18.87 & 1.44 & 22.9 & 30.5 \\
\hline T5M & 19.33 & 1.44 & 22.4 & 29.8 \\
\hline T6M & 19.63 & 1.66 & 25.4 & 33.8 \\
\hline T7M & 19.88 & 1.83 & 27.6 & 36.8 \\
\hline T8M & 20.19 & 2.02 & 30.1 & 40.1 \\
\hline T9M & 20.81 & 1.93 & 27.9 & 37.2 \\
\hline T10M & 21.70 & 1.83 & 25.3 & 33.8 \\
\hline $\mathrm{T} 11 \mathrm{M}$ & 22.90 & 1.92 & 25.1 & 33.4 \\
\hline $\mathrm{T} 12 \mathrm{M}$ & 24.61 & 3.00 & 36.6 & 48.7 \\
\hline L1M & 26.52 & 3.29 & 37.2 & 49.7 \\
\hline L2M & 27.35 & 2.96 & 32.5 & 43.3 \\
\hline L3M & 27.94 & 2.53 & 27.2 & 36.3 \\
\hline L4M & 27.57 & 2.80 & 30.5 & 40.6 \\
\hline T4P & 20.57 & 1.68 & 24.6 & 32.8 \\
\hline T5P & 21.26 & 1.60 & 22.6 & 30.1 \\
\hline T6P & 21.83 & 1.57 & 21.6 & 28.8 \\
\hline T7P & 22.21 & 1.68 & 22.7 & 30.2 \\
\hline T8P & 22.25 & 1.70 & 22.9 & 30.5 \\
\hline T9P & 22.37 & 1.69 & 22.7 & 30.2 \\
\hline $\mathrm{T} 10 \mathrm{P}$ & 23.44 & 1.68 & 21.5 & 28.6 \\
\hline $\mathrm{T} 11 \mathrm{P}$ & 25.19 & 1.95 & 23.2 & 31.0 \\
\hline $\mathrm{T} 12 \mathrm{P}$ & 27.67 & 2.18 & 23.7 & 31.6 \\
\hline L1P & 29.72 & 2.19 & 22.1 & 29.4 \\
\hline L2P & 30.09 & 2.03 & 20.3 & 27.0 \\
\hline L3P & 29.70 & 2.02 & 20.4 & 27.2 \\
\hline$\llcorner 4 \mathrm{P}$ & 27.95 & 2.22 & 23.9 & 31.8 \\
\hline
\end{tabular}

of impaired function or disability [13, 40, 41]. Vertebral compression fractures are likely to cause functional limitations, such as difficulty with ADL and physical performance.
Abnormal trunk posture resulting from vertebral compression fractures has been reported to be associated with functional disabilities [42, 43]. AntonelliIncalzi et al. [44] showed that longer occiput-wall 
Table 3 Means (SD) of physical performance measures by age group

\begin{tabular}{lllllll}
\hline Age group (years) & $\begin{array}{l}40-49 \\
(n=41)\end{array}$ & $\begin{array}{l}50-59 \\
(n=118)\end{array}$ & $\begin{array}{l}60-69 \\
(n=211)\end{array}$ & $\begin{array}{l}70-79 \\
(n=161)\end{array}$ & $\begin{array}{l}80- \\
(n=25)\end{array}$ \\
\hline Walking speed $(\mathrm{m} / \mathrm{s})$ & $1.44(0.20)$ & $1.34(0.19)$ & $1.29(0.22)$ & $1.10(0.22)$ & $0.93(0.24)$ & $<0.0001$ \\
Chair stand time $(\mathrm{s})$ & $6.7(1.2)$ & $8.1(1.7)$ & $9.1(2.3)$ & $10.7(3.1)$ & $13.4(6.2)$ & $<0.0001$ \\
Functional reach $(\mathrm{cm})$ & $33.0(5.9)$ & $29.8(6.1)$ & $25.0(6.3)$ & $22.6(6.4)$ & $18.2(6.4)$ & $<0.0001$ \\
\hline
\end{tabular}

distance, which indirectly evaluates thoracic kyphosis due to vertebral compression fractures [45], was associated with slower walking speed, reduced balance, and longer chair stand time in elderly women. Hirose et al.
[46] showed that abnormal posture of the trunk (thoracic and lumbar kyphosis) was associated with slower walking speed and shorter functional reach among the community-dwelling elderly population. In our study,

Table 4 Multivariate-adjusted mean (standard error) of walking speed, chair stand time and functional reach according to number of vertebral compression fractures

\begin{tabular}{|c|c|c|c|}
\hline & Vertebral compression fracture & Adjusted mean (SE) & $P$ value \\
\hline \multirow[t]{3}{*}{ Walking speed $(\mathrm{m} / \mathrm{s})$} & No & $1.24(0.01)$ & \\
\hline & One & $1.23(0.03)$ & 0.68 \\
\hline & Two or more & $1.17(0.03)$ & $0.03^{a}$ \\
\hline Adjusted factors & & Estimate (SE) & \\
\hline Age (year) & +1 year & $-0.012(0.001)$ & $<0.001$ \\
\hline BMI & $+1 \mathrm{~kg} / \mathrm{m}^{2}$ & $-0.003(0.003)$ & 0.22 \\
\hline Back pain & 1 , yes; 0 , no & $-0.023(0.020)$ & 0.24 \\
\hline No. of non-spine painful joints & +1 & $-0.018(0.004)$ & $<0.001$ \\
\hline No. of comorbidity & +1 & $-0.039(0.014)$ & 0.005 \\
\hline Regular physical activity & 1 , yes; 0 , no & $0.041(0.017)$ & 0.02 \\
\hline \multirow[t]{3}{*}{ Chair stand time (s) } & No & $9.3(0.1)$ & \\
\hline & One & $9.6(0.4)$ & 0.41 \\
\hline & Two or more & $10.4(0.4)$ & $0.01^{a}$ \\
\hline \multicolumn{4}{|l|}{ Adjusted factors } \\
\hline Age (year) & +1 year & $0.14(0.13)$ & $<0.001$ \\
\hline BMI & $+1 \mathrm{~kg} / \mathrm{m}^{2}$ & $-0.004(0.03)$ & 0.91 \\
\hline Back pain & 1 , yes; 0 , no & $0.04(0.25)$ & 0.87 \\
\hline No. of non-spine painful joints & +1 & $0.16(0.05)$ & 0.003 \\
\hline No. of comorbidity & +1 & $0.25(0.18)$ & 0.16 \\
\hline Regular physical activity & 1 , yes; 0 , no & $-0.70(0.22)$ & 0.002 \\
\hline \multirow[t]{3}{*}{ Functional reach $(\mathrm{cm})$} & No & $25.9(0.3)$ & \\
\hline & One & $24.7(1.0)$ & 0.28 \\
\hline & Two or more & $23.2(1.0)$ & $0.01^{a}$ \\
\hline \multicolumn{4}{|l|}{ Adjusted factors } \\
\hline Age (year) & +1 year & $-0.37(0.03)$ & $<0.001$ \\
\hline BMI & $+1 \mathrm{~kg} / \mathrm{m}^{2}$ & $-0.12(0.08)$ & 0.12 \\
\hline Back pain & 1 , yes; 0 , no & $-0.85(0.60)$ & 0.16 \\
\hline No. of non-spine painful joints & +1 & $0.08(0.13)$ & 0.52 \\
\hline No. of comorbidity & +1 & $-0.04(0.42)$ & 0.92 \\
\hline Regular physical activity & 1 , yes; 0 , no & $0.17(0.53)$ & 0.75 \\
\hline
\end{tabular}

$B M I$ Body mass index

${ }^{a}$ compared with women without compression fracture 
longer chair stand time was associated with one thoracic compression fracture, and shorter functional reach was associated with two or more thoracic compression fracture.

We previously reported that spinal posture in forward inclination was associated with impaired physical performance in 6-m walking time, chair stand time, and functional reach [39]. Lyles et al. [23] postulated that osteoporotic compression fractures affect the alignment of the entire trunk, leading to a reduction in motion and strength. The shift forward in the center of gravity that occurs with progressive kyphosis from vertebral compression fracture could make trunk movements in a forward direction more unsteady and limited.

Some vertebral compression fractures are associated with increased risk of back pain [22, 25, 47]. In situations in which both vertebral compression fracture and back pain are present, functional losses could occur from the symptoms caused by the compression fracture and/or from the alteration in trunk alignment [29]. In this study, having vertebral compression fractures was significantly associated with poor physical performance independent of back pain and other covariates. These results possibly mean vertebral compression fractures affect physical performances via abnormal trunk posture.

Comorbidities are associated with decreased physical function, and the more the number of comorbidities is, the poorer the physical function is [48]. Thus, we included the number of comorbidities in the model as a covariate.

Our definition of vertebral compression fracture used the vertebral height and its SD, according to Ross et al. [34]; they reported that the cutoff of 3 SD rarely misclassified normal vertebrae as fractured (specificity= 99.9\%). However, this cutoff correctly identified about $70 \%$ of the incident fractures. A less stringent criterion ( 2 SD below the mean: specificity $=97.7 \%$ ) identified about $85-90 \%$ of true fractures. Thus, our results may have underestimated the prevalence of compression fractures, which may contribute to Type II error of the association.

The study has several limitations. First, because this was a cross-sectional design, a causal relationship was not necessarily shown by our results. Longitudinal studies are required to clarify the relationships between vertebral compression fracture and physical performance. Second, the subjects were community-dwelling women who voluntarily participated; women with poorer physical performance might not have participated in the present study, which might have affected the results. Third, there are no results of the Timed Up \& Go Test of physical performance in our analysis. Fourth, the present study included only Japanese women; therefore, it may be not possible to extrapolate the results to men or people of other ethnicities. Nevertheless, the present data clearly showed an association of vertebral compression fracture with deterioration of physical performance, independent of age and other covariates.

\section{Conclusion}

Our results suggest that multiple vertebral compression fractures affect physical performance (slower walking speed, lower chair stand time and shorter functional reach) in community-dwelling Japanese women, independent of age and other covariates. Because poor physical functioning may lead to functional dependence, accelerated bone loss, and increased risk for falls, injuries (e.g., sprain, abrasion, laceration or dislocation after falling), and fractures [25], preventing vertebral compression fracture is important for the preservation of older adults' independence.

\section{Abbreviations}

ADL: Activities of daily living; BMl: Body mass index

\section{Acknowledgements \\ None.}

Funding

Not applicable.

Availability of data and materials

Not applicable. We are planning to conduct a longitudinal analysis. Thus, we cannot share the baseline raw data in this study.

\section{Authors' contributions}

Making substantial contributions to conception and design: KA, YA, TN, TO, YT and KA. Acquisition of data: KA, YA, TN, TO, YT, SM, MK. Analysis and interpretation of data: KA, YA, TN and KA. Drafting the manuscript: KA, YA, $\mathrm{TN}, \mathrm{YT}$ and KA. All authors read and approved the final manuscript.

\section{Competing interests}

The authors declare that they have no competing interest.

\section{Consent for publication}

Not applicable.

Ethics approval and consent to participants

This study was approved by the Oshima ethics committee. All subjects gave written informed consent before enrolling.

\section{Publisher's Note}

Springer Nature remains neutral with regard to jurisdictional claims in published maps and institutional affiliations.

\section{Author details}

${ }^{1}$ Department of Public Health, Nagasaki University Graduate School of Biomedical Sciences, 1-12-4 Sakamoto, Nagasaki 852-8523, Japan.

${ }^{2}$ Department of Rehabilitation, Nishi-Isahaya Hospital, Isahaya, Japan.

Received: 9 November 2016 Accepted: 17 April 2017

Published online: 28 April 2017

\section{References}

1. Nih Consensus Development Panel on Osteoporosis Prevention D. Therapy: Osteoporosis prevention, diagnosis, and therapy. JAMA. 2001;285(6):785-95.

2. Yoshimura N, Muraki S, Oka H, Mabuchi A, En-Yo Y, Yoshida M, Saika A, Yoshida H, Suzuki T, Yamamoto S, et al. Prevalence of knee osteoarthritis, lumbar spondylosis, and osteoporosis in Japanese men and women: the 
research on osteoarthritis/osteoporosis against disability study. J Bone Miner Metab. 2009;27(5):620-8.

3. Ross PD. Clinical consequences of vertebral fractures. Am J Med. 1997; 103(2A):30S-42. discussion 42S-43S.

4. Eastell R, Cedel SL, Wahner HW, Riggs BL, Melton 3rd LJ. Classification of vertebral fractures. J Bone Miner Res. 1991;6(3):207-15.

5. Sadat-Ali M, Gullenpet AH, Al-Mulhim F, Al Turki H, Al-Shammary H, Al-Elq A, Al-Othman A. Osteoporosis-related vertebral fractures in postmenopausal women: prevalence in a Saudi Arabian sample. East Mediterr Health J. 2009; 15(6):1420-5.

6. Clark P, Cons-Molina F, Deleze M, Ragi S, Haddock L, Zanchetta JR, Jaller JJ, Palermo L, Talavera JO, Messina DO, et al. The prevalence of radiographic vertebral fractures in Latin American countries: the Latin American Vertebral Osteoporosis Study (LAVOS). Osteoporos Int. 2009;20(2):275-82.

7. Spector TD, McCloskey EV, Doyle DV, Kanis JA. Prevalence of vertebral fracture in women and the relationship with bone density and symptoms: the Chingford Study. J Bone Miner Res. 1993;8(7):817-22.

8. O'Neill TW, Felsenberg D, Varlow J, Cooper C, Kanis JA, Silman AJ. The prevalence of vertebral deformity in european men and women: the European Vertebral Osteoporosis Study. J Bone Miner Res. 1996;11(7):1010-8.

9. Fechtenbaum J, Cropet C, Kolta S, Verdonca B, Orcel P, Roux C. Reporting of vertebral fractures on spine X-rays. Osteoporos Int. 2005;16(12):1823-6.

10. McKiernan FE. The broadening spectrum of osteoporotic vertebral fracture. Skeletal Radiol. 2009;38(4):303-8.

11. Harada A, World Health O. Absolute risk for fracture and WHO guideline. Economic analysis of pharmacotherapy for osteoporosis. Clin Calcium. 2007; 17(7):1029-34

12. Perkowski LC, Stroup-Benham CA, Markides KS, Lichtenstein MJ, Angel RJ, Guralnik JM, Goodwin JS. Lower-extremity functioning in older Mexican Americans and its association with medical problems. J Am Geriatr Soc. 1998;46(4):411-8.

13. Ensrud KE, Nevitt MC, Yunis C, Cauley JA, Seeley DG, Fox KM, Cummings SR. Correlates of impaired function in older women. J Am Geriatr Soc. 1994; 42(5):481-9.

14. Kim MJ, Yabushita N, Kim MK, Matsuo T, Okuno J, Tanaka K. Alternative items for identifying hierarchical levels of physical disability by using physical performance tests in women aged 75 years and older. Geriatr Gerontol Int. 2010;10(4):302-10.

15. Morita M, Takamura N, Kusano Y, Abe Y, Moji K, Takemoto T, Aoyagi K. Relationship between falls and physical performance measures among community-dwelling elderly women in Japan. Aging Clin Exp Res. 2005; 17(3):211-6.

16. Nevitt MC, Cummings SR, Kidd S, Black D. Risk factors for recurrent nonsyncopal falls. A prospective study. JAMA. 1989;261(18):2663-8.

17. Davis JW, Ross PD, Nevitt MC, Wasnich RD. Risk factors for falls and for serious injuries on falling among older Japanese women in Hawaii. J Am Geriatr Soc. 1999;47(7):792-8.

18. Cummings SR, Nevitt MC, Browner WS, Stone K, Fox KM, Ensrud KE, Cauley J, Black D, Vogt TM. Risk factors for hip fracture in white women. Study of Osteoporotic Fractures Research Group. N Engl J Med. 1995;332(12):767-73.

19. Aoyagi K, Ross PD, Hayashi T, Okano K, Moji K, Sasayama H, Yahata Y, Takemoto T. Calcaneus bone mineral density is lower among men and women with lower physical performance. Calcif Tissue Int. 2000;67(2):106-10.

20. Cawthon PM, Fullman RL, Marshall L, Mackey DC, Fink HA, Cauley JA, Cummings SR, Orwoll ES, Ensrud KE. Osteoporotic Fractures in Men Research G: Physical performance and risk of hip fractures in older men. J Bone Miner Res. 2008;23(7):1037-44

21. Ross PD, Ettinger B, Davis JW, Melton 3rd L, Wasnich RD. Evaluation of adverse health outcomes associated with vertebral fractures. Osteoporos Int 1991;1(3):134-40

22. Ettinger B, Black DM, Nevitt MC, Rundle AC, Cauley JA, Cummings SR, Genant HK. Contribution of vertebral deformities to chronic back pain and disability. The Study of Osteoporotic Fractures Research Group. J Bone Miner Res. 1992;7(4):449-56.

23. Lyles KW, Gold DT, Shipp KM, Pieper CF, Martinez S, Mulhausen PL. Association of osteoporotic vertebral compression fractures with impaired functional status. Am J Med. 1993:94(6):595-601.

24. Ross PD, Davis JW, Epstein RS, Wasnich RD. Pain and disability associated with new vertebral fractures and other spinal conditions. J Clin Epidemiol. 1994:47(3):231-9.
25. Huang C, Ross PD, Wasnich RD. Vertebral fracture and other predictors of physical impairment and health care utilization. Arch Intern Med. 1996; 156(21):2469-75.

26. Pluijm SM, Tromp AM, Smit JH, Deeg DJ, Lips P. Consequences of vertebral deformities in older men and women. J Bone Miner Res. 2000;15(8):1564-72.

27. Jinbayashi $H$, Aoyagi K, Ross PD, Ito M, Shindo H, Takemoto T. Prevalence of vertebral deformity and its associations with physical impairment among Japanese women: The Hizen-Oshima Study. Osteoporos Int. 2002;13(9):723-30.

28. O'Neill TW, Cockerill W, Matthis C, Raspe HH, Lunt M, Cooper C, Banzer D, Cannata JB, Naves M, Felsch B, et al. Back pain, disability, and radiographic vertebral fracture in European women: a prospective study. Osteoporos Int. 2004;15(9):760-5.

29. Edmond SL, Kiel DP, Samelson EJ, Kelly-Hayes M, Felson DT. Vertebral deformity, back symptoms, and functional limitations among older women: the Framingham Study. Osteoporos Int. 2005;16(9):1086-95.

30. Cawthon PM, Blackwell TL, Marshall LM, Fink HA, Kado DM, Ensrud KE, Cauley JA, Black D, Orwoll ES, Cummings SR, et al. Physical performance and radiographic and clinical vertebral fractures in older men. J Bone Miner Res. 2014;29(9):2101-8.

31. Yoshida S, Aoyagi K, Felson DT, Aliabadi P, Shindo H, Takemoto T. Comparison of the prevalence of radiographic osteoarthritis of the knee and hand between Japan and the United States. J Rheumatol. 2002;29(7):1454-8.

32. Gallagher JC, Hedlund LR, Stoner S, Meeger C. Vertebral morphometry: normative data. Bone Miner. 1988;4(2):189-96.

33. Spencer NESP, Cummings SR, Genant HK. Placement of points for digitizing spine films. J Bone Miner Res (abstract). 1990;5 Suppl 2:247.

34. Ross PD, Davis JW, Epstein RS, Wasnich RD. Ability of vertebral dimensions from a single radiograph to identify fractures. Calcif Tissue Int. 1992;51(2):95-9.

35. Imms FJ, Edholm OG. Studies of gait and mobility in the elderly. Age Ageing. 1981;10(3):147-56.

36. Csuka M, McCarty DJ. Simple method for measurement of lower extremity muscle strength. Am J Med. 1985;78(1):77-81.

37. Duncan PW, Weiner DK, Chandler J, Studenski S. Functional reach: a new clinical measure of balance. J Gerontol. 1990;45(6):M192-7.

38. Davis JW, Ross PD, Preston SD, Nevitt MC, Wasnich RD. Strength, physical activity, and body mass index: relationship to performance-based measures and activities of daily living among older Japanese women in Hawaii. J Am Geriatr Soc. 1998;46(3):274-9.

39. Abe Y, Aoyagi K, Tsurumoto T, Chen CY, Kanagae M, Mizukami S, Ye Z, Kusano $Y$. Association of spinal inclination with physical performance measures among community-dwelling Japanese women aged 40 years and older. Geriatr Gerontol Int. 2013;13(4):881-6.

40. Fried LP, Young Y, Rubin G, Bandeen-Roche K. Self-reported preclinical disability identifies older women with early declines in performance and early disease. J Clin Epidemiol. 2001;54(9):889-901.

41. Weiner DK, Duncan PW, Chandler J, Studenski SA. Functional reach: a marker of physical frailty. J Am Geriatr Soc. 1992;40(3):203-7.

42. Kado DM, Huang MH, Barrett-Connor E, Greendale GA. Hyperkyphotic posture and poor physical functional ability in older community-dwelling men and women: the Rancho Bernardo study. J Gerontol A Biol Sci Med Sci. 2005;60(5):633-7.

43. Takahashi T, Ishida K, Hirose D, Nagano Y, Okumiya K, Nishinaga M, Matsubayashi K, Doi Y, Tani T, Yamamoto H. Trunk deformity is associated with a reduction in outdoor activities of daily living and life satisfaction in community-dwelling older people. Osteoporos Int. 2005;16(3):273-9.

44. Antonelli-Incalzi R, Pedone C, Cesari M, Di lorio A, Bandinelli S, Ferrucci L. Relationship between the occiput-wall distance and physical performance in the elderly: a cross sectional study. Aging Clin Exp Res. 2007;19(3):207-12.

45. Green AD, Colon-Emeric CS, Bastian L, Drake MT, Lyles KW. Does this woman have osteoporosis? JAMA. 2004;292(23):2890-900.

46. Hirose D, Ishida K, Nagano Y, Takahashi T, Yamamoto H. Posture of the trunk in the sagittal plane is associated with gait in community-dwelling elderly population. Clin Biomech (Bristol, Avon). 2004;19(1):57-63.

47. Kitahara H, Ye Z, Aoyagi K, Ross PD, Abe Y, Honda S, Kanagae M, Mizukami S, Kusano Y, Tomita M, et al. Associations of vertebral deformities and osteoarthritis with back pain among Japanese women: the Hizen-Oshima study. Osteoporos Int. 2013;24(3):907-15.

48. Groll DL, To T, Bombardier C, Wright JG. The development of a comorbidity index with physical function as the outcome. J Clin Epidemiol. 2005;58(6): 595-602. 